\title{
Effect of Förster Energy Transfer and Hole Transport Layer on Performance of Polymer Light-E mitting Diodes
}

\section{Liming Ding, Frank E. Karasz,* Zhiqun Lin, and Min Zheng}

Department of Polymer Science \& Engineering, University of Massachusetts, Amherst, Massachusetts 01003

\section{Liang Liao and Yi Pang}

Department of Chemistry, Clark Atlanta University, Atlanta, Georgia 30314

Received J une 28, 2001; Revised Manuscript Received September 27, 2001

\begin{abstract}
The novel viol et-blue-emitting electrol uminescent polymer I was blended at three different weight ratios with the green-emitting polymer II, providing materials which have been studied in terms of their absorbance, photoluminescence, electroluminescence, and morphology. The absorption and PL spectra in dilute solution and in the solid state were compared. Substantial red shifts were observed in photol uminescence from the solid state, which were attributed to intermol ecular interactions in the films. Only green emission was obtained from films of the polymer blends and from corresponding double-layer LEDs, indicating an al most complete Förster energy transfer from I to II. Morphologi cal studies indicate that the immiscibility of the two polymers and their differences in $\mathrm{CHCl}_{3}$ solubility result in submicron phase separation during film preparation. In a blend with a high concentration of I, large domains of I were responsible for an incomplete energy transfer, especially noticeable in the solid-state photol uminescence. In double-layer LEDs, both PPV and polyethylene dioxythiophene/polystyrene sulfonate (PEDOT/ PSS) were used as hole-transport layers to increase device efficiency. At $8 \mathrm{~V}$ bias, bright green emission $\left(2700 \mathrm{~cd} / \mathrm{m}^{2}\right)$ was observed in an ITO/PEDOT/II/Ca device with an external quantum efficiency of $0.69 \%$. The effectiveness of the two hole-transport materials was compared.
\end{abstract}

\section{Introduction}

Since the first report ${ }^{1}$ of light-emitting diodes (LEDs) based on poly(p-phenylenevinylene) (PPV), much work ${ }^{2}$ has been carried out with the objective of tuning the emission color and improving quantum efficiency and stability. Concurrently, conjugated polymers also find other applications in light-emitting electrochemical cells (LECs), ${ }^{3}$ photodiodes, ${ }^{4,5}$ transistors, ${ }^{6}$ and lasers. ${ }^{7,8}$ These materials have the advantage of a facile col or tunability, of good film-forming property, and of adequate mechanical properties in comparison to inorganic semi conductors. All these features have given the material potential for practical application in optoelectronics.

In LED investigations, tunability of the emission spectrum to any desired color including white still presents interesting challenges. Up to now five methods have been reported for tuning the emission of polymer LEDs: changing the main-chain molecular structure, ${ }^{9,10}$ changing the side-chain molecular structure, ${ }^{11}$ blending an electroluminescent polymer with a second active polymer ${ }^{12,13}$ or with low molecular weight organic ${ }^{14}$ or inorganic molecules, ${ }^{15}$ doping, ${ }^{16}$ and using multilayer device architectures. ${ }^{17}$ Polymer blending provides a simple, low-cost, and sometimes very effective way to obtain new materials for use in LEDs. By carefully selecting different luminescent polymers for blending and by controlling the content of the target chromophore in the blend, one can obtain different emission colors from a LED with reasonable quantum efficiency. ${ }^{18}$ Heeger et al. ${ }^{13,18,19}$ also systematically studied conjugated polymer blends in LEDs, demonstrating enhanced electroluminescence from the P3HT/ME H - PPV blend ${ }^{18}$ and noting that the blue shift of the $\pi-\pi^{*}$ transition of PPPV in PVK results in a blue luminescence and electroluminescence. ${ }^{13}$
In previous studies, our group has designed and synthesized a green emitting copolymer II with welldefined isolated chromophore structure $\mathrm{e}^{20}$ (F igure 1 ). The polymer contains alternating rigid and flexible blocks in which the former have a mol ecular structure analogous to the appropriate low molar mass conjugated molecules while the latter are methylene blocks. The rigid blocks as specified in polymer II determine the band gap and the photoluminescence and electroluminescence spectra. The flexible blocks contribute to the solubility and film-forming properties of the material.

In this contribution, we present studies of absorbance, photol uminescence $(P L)$, el ectrol umi nescence $(E L)$ and morphology of polymer blends of II and a novel violetblue electroluminescent polymer I (Figure 1). Absorbance and PL of the blends in solution and solid state are compared with that of the pristine polymers. The Förster energy transfer 21,22 phenomena occurring in the solid-state $\mathrm{PL}$ and $\mathrm{EL}$ are discussed in terms of the blend morphology. The voltage dependence of the observed EL spectra is explained and the performance of double-layer LEDs using either PPV or PEDOT as holetransport layers are compared with the corresponding single-layer LED.

\section{Experimental Section}

Polymer Synthesis and Characterization. Polymer I was synthesized by reacting isophthal dehyde with 2-hexoxy5-methyl-1,3-xylylene tetraethyl diphosphonate in the presence of potassium tert-butoxide at room temperature. ${ }^{23}$ Polymer II was synthesized according to a previous procedure. ${ }^{20} \mathrm{UV}$-vis spectra were recorded on an IBM 9420 UV-visible spectrophotometer. PL spectra were obtained on a Perkin-EImer LS 50B luminescence spectrometer with a xenon light source. An Olympus microscope (Model BX60) was used for optical microscopy. AFM was performed with a NanoScope IIIa 
<smiles>CC=Cc1cc(C)cc(C=Cc2cccc(C)c2)c1OC</smiles>

Polymer I

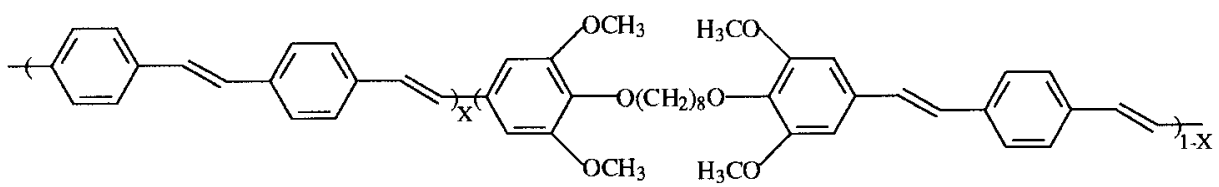

$\mathrm{X}=0.2$

Polymer II

Figure 1. Structures of polymer I and polymer II.

(Digital Instruments) in the tapping mode. Small-angle light scattering (SALS) was carried out on a custom apparatus with a $10 \mathrm{~mW}$ He-Nelaser $(632.8 \mathrm{~nm})$ as light source which detects domain sizes larger than $1 \mu \mathrm{m}$. The polymers were dissolved in chloroform to $10^{-5} \mathrm{M}$ dilution for solution measurements. Solid-state films were obtained by spin casting a $20 \mathrm{mg} / \mathrm{mL}$ polymer/chloroform solution on to glass substrates with a spinning speed of $4000 \mathrm{rpm}$.

LED Fabrication and Measurement. PEDOT/PSS (Bayer Co.) was spin-cast on to ITO glass (OFC Co.) used as an anode. The polymer solutions ( $20 \mathrm{mg} / \mathrm{mL}$ in chloroform) were filtered through $0.2 \mu \mathrm{m}$ Millex-F GS Filters (Millipore Co.) and then spin-cast on to ITO glass or on to the dried PEDOT/ ITO substrates under a nitrogen atmosphere. The polymer films were typically $75 \mathrm{~nm}$ thick. PPV/ITO substrates were made by spin-casting onto the ITO surface with a methanol solution of the PPV precursor. ${ }^{1}$ The precursor layer was eliminated at $250{ }^{\circ} \mathrm{C}$ for $2 \mathrm{~h}$ under an argon atmosphere. Calcium electrodes of $400 \mathrm{~nm}$ thickness were evaporated onto the polymer at about $10^{-7}$ Torr, followed by a protective coating of aluminum. The devices were characterized using a system constructed in our laboratory described elsewhere.17

\section{Results and Discussion}

Absorbance. Polymer blends were obtained by mixing polymer I and II in chloroform with different weight ratios; namely $2: 1,1: 1$, and $1: 2$. The absorption spectra of $\mathbf{I}, \mathbf{I}$, and the blends, both in solution and in the solid state, are shown in Figure 2, and the peak wavelengths are listed in Table 1. In solution, the onset (the intersection of the slope and baseline extrapolation) of the $\pi-\pi^{*}$ transition of I and II are at $\sim 382$ and $\sim 459 \mathrm{~nm}$, respectively, while the absorption peaks are at 309 and $376 \mathrm{~nm}$ (Figure 2a). In the blends, the absorption spectra are the weight-averaged sum of the individual absorbance contribution from the two polymers as anticipated. For the 2:1 blend, the absorption spectrum has one peak at $311 \mathrm{~nm}$. While both the 1:1 and 1:2 blends have two resolved peaks, those at 312 (1:1 blend) and 318 ( $1: 2$ blend) $\mathrm{nm}$ are attributed to polymer $\mathbf{I}$, and the 352 (1:1 blend) and 371 (1:2 blend) nm peaks, to polymer II. In the solid state, the onset of the $\pi-\pi^{*}$ transitions of I and II are at $\sim 388$ and $\sim 466 \mathrm{~nm}$ respectively, with a small red shift compared to the corresponding sol ution spectra; the absorption peaks of the films I and II are at 306 and $376 \mathrm{~nm}$ respectively (Figure $2 b$ ), very similar to that of their respective solution spectra. These results indicate that there are only minor differences between the solid state and the solution absorbances.
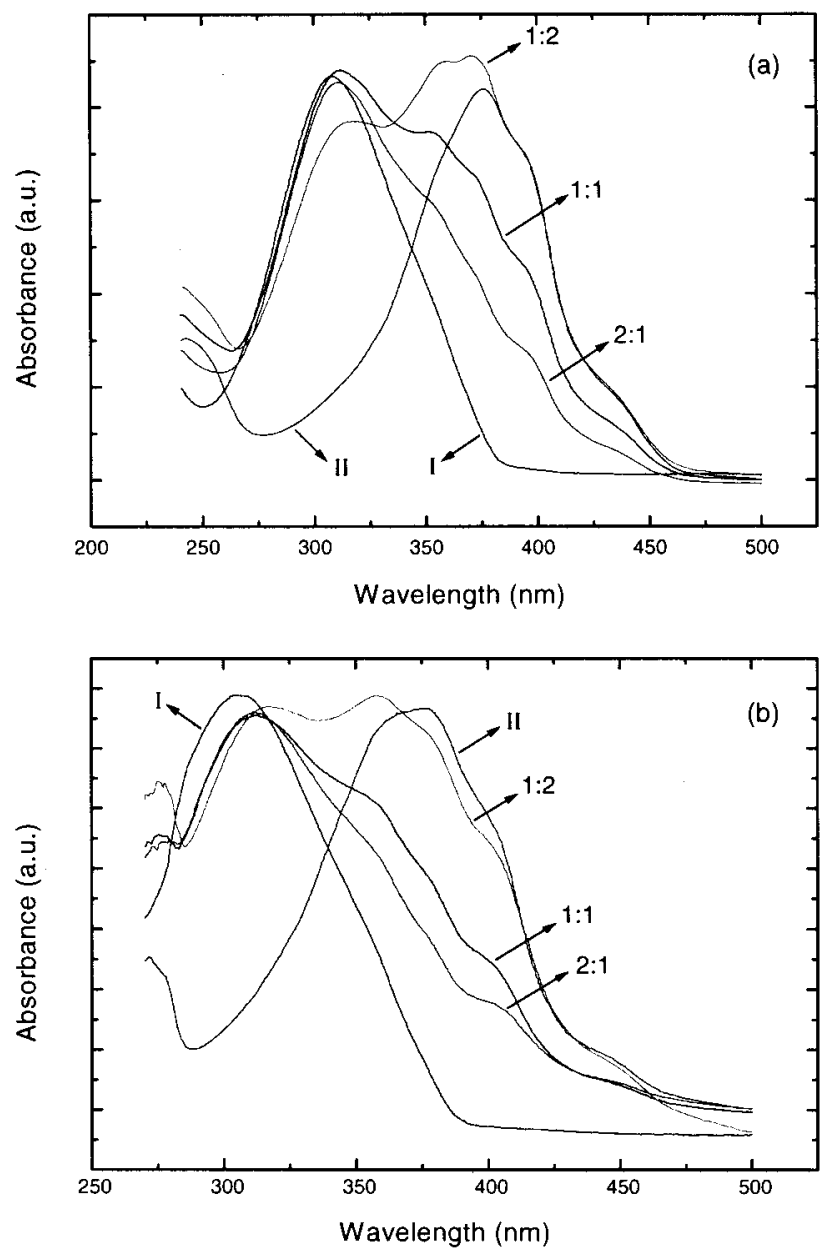

Figure 2. Absorption spectra for polymer $\mathbf{I}$, the $2: 1,1: 1$, and 1:2 blends, and polymer II: (a) chloroform solution $\left(10^{-5} \mathrm{M}\right)$; (b) solid state.

Photoluminescence. The solution photoluminescence spectra (Figure $3 a$ ) were recorded with excitation wavelengths corresponding to the solution absorption peak wavelengths of the samples. The solid-state PL spectra (Figure 3b) were obtained by exciting the samples with $376 \mathrm{~nm}$ light. The peak wavelengths are shown in Table 1. Pure polymers I and II in chloroform showed fluorescence maxima at 424 and $455 \mathrm{~nm}$, respectively. The PL spectrum of II exhibits a wellresolved peak at $455 \mathrm{~nm}(2.73 \mathrm{eV})$ and two shoulders at about $420(2.95 \mathrm{eV})$ and $479 \mathrm{~nm}(2.59 \mathrm{eV})$, which 
Table 1. Absorbance, Photoluminescence, and Electroluminescence Results ${ }^{\mathrm{a}}$

\begin{tabular}{|c|c|c|c|c|c|c|}
\hline \multirow[b]{3}{*}{ polymer } & \multirow{2}{*}{\multicolumn{2}{|c|}{$\lambda_{\max }{ }^{\mathrm{ABS}}(\mathrm{nm})$}} & \multirow{2}{*}{\multicolumn{2}{|c|}{$\lambda_{\max }{ }^{P L}(n m)$}} & \multicolumn{2}{|c|}{$\lambda_{\max }{ }^{E L}(n m)$} \\
\hline & & & & & \multirow{2}{*}{$\begin{array}{l}\text { single } \\
\text { layer }\end{array}$} & \multirow{2}{*}{$\begin{array}{l}\text { double } \\
\text { layer }\end{array}$} \\
\hline & solution & film & solution & filmb & & \\
\hline I & 309 & 306 & 424 & 445,458 & 437,454 & 445, 462 \\
\hline $2: 1$ & 311 & 312 & 424, 449 & 509 & 494 & 508,535 \\
\hline 1:1 & $\mathbf{3 1 2}, 352$ & 312 & 426,451 & 513 & 499 & 513,541 \\
\hline $1: 2$ & 318, 371 & 317, 358 & 454 & $\mathbf{5 1 4}, 530$ & 505 & 509,539 \\
\hline II & 376 & 376 & 455 & 517,530 & 513,539 & 509,537 \\
\hline
\end{tabular}

a Bold data indicate the major peak. ${ }^{b} 376 \mathrm{~nm}$ excitation wave length.
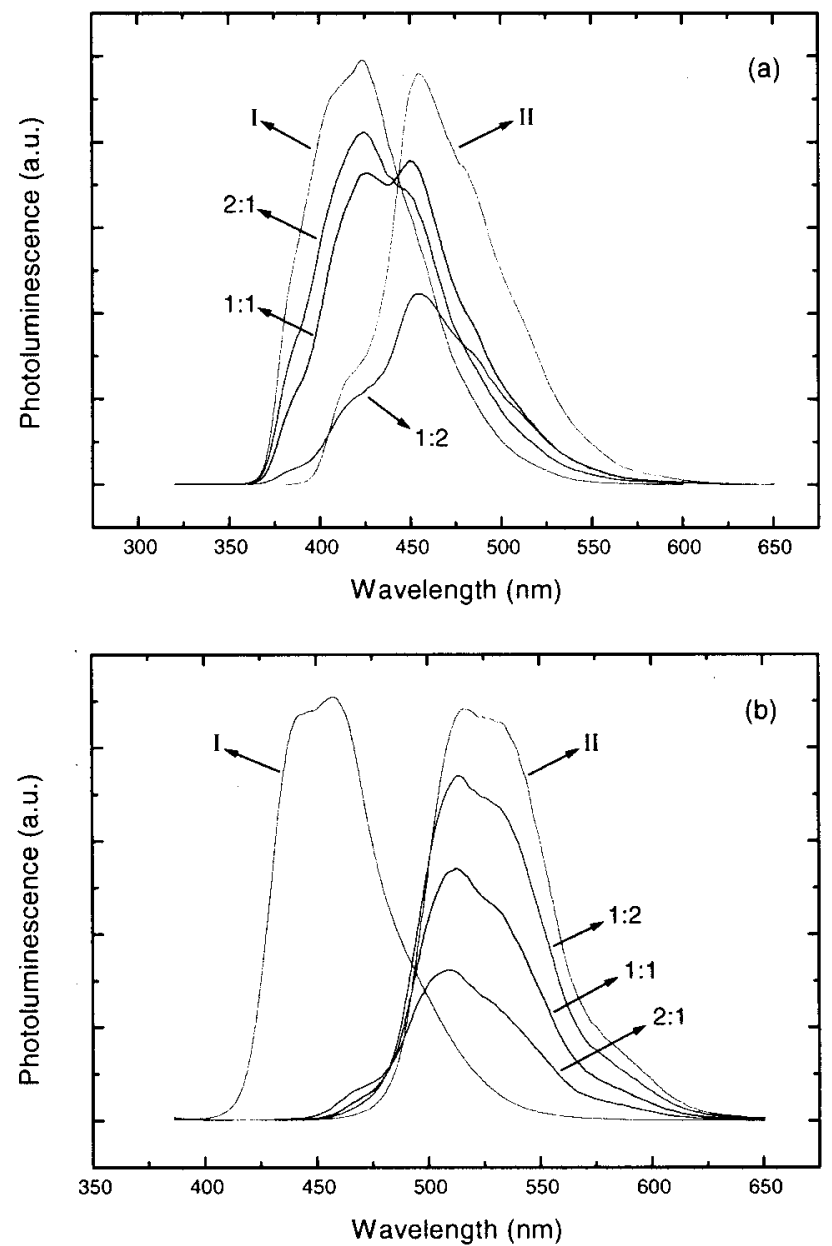

Figure 3. Photoluminescence spectra for polymer $\mathbf{I}$, the $2: 1$, 1:1, and 1:2 blends, and polymer II: (a) chloroform solution $\left(10^{-5} \mathrm{M}\right)$; (b) solid state, excited at $376 \mathrm{~nm}$.

could be attributed to its $0-1,0-0$, and $0-2$ transitions, respectively. In the PL spectra of the blends in solution, the contribution from each polymer can be observed.

The comparison of the film fluorescence spectra, Figure $3 b$, with the corresponding solution spectra, Figure 3a, shows major differences. The solid-state PL spectra of I or II is composed of two peaks, for polymer I at 445 and $458 \mathrm{~nm}$ and for II at 517 and $530 \mathrm{~nm}$. In addition red shifts occur in the solid state, about 34 and $62 \mathrm{~nm}$ for I and II respectively. The shape changes for $\mathrm{PL}$ spectra, and the red shifts are due to intermolecular interactions in the films. In the solid state, the blends display only green emission of 509-514 nm with the characteristic of polymer II, suggesting a strong Förster energy transfer from the violet-blue polymer I to the green polymer II. When $306 \mathrm{~nm}$ excitation is used, corresponding to the absorption peak wavelength for polymer I, very similar results are obtained, namely a 506-513 nm green emission from the blends, indicating that energy transfer is independent of excitation wavelength.

To obtain efficient Förster energy transfer, it is necessary to have substantial spectral overlap between the emission of the host polymer with higher band gap and the absorption of the guest polymer with lower band gap, and an intimate mixing of the two species. ${ }^{22,24}$ In this work, the PL spectrum for polymer I film and the absorption spectrum for polymer II film overlap to a reasonable extent in the $400-500 \mathrm{~nm}$ region to satisfy the basic requirement for energy transfer from I to II. In very dilute solution, the dipole-dipole distance is larger than the required Förster range, thus there is no interaction and finally no energy transfer. In future spectroscopic studies, the parameters required to evaluate the Förster range $\mathrm{R}_{0}$ will be acquired.

Morphology. Optical microscopy measurements showed that there were no macroscopic domains in the polymer blends. The surfaces of the blend films at this scale are uniform. These results were confirmed by a SALS measurement, in which the absence of a spinodal ring scattering pattern indicated that the size of any separate phases, if present, is smaller than $1 \mu \mathrm{m}$.

The morphology for the films of the two pure polymers and of the three blends was studied by AFM. The height images are shown in Figure 4. I mage analysis indicates that the root-mean-square (RMS) roughness for the films of polymer $\mathbf{I}$, of the $2: 1,1: 1$, and $1: 2$ blends, and of polymer II were 3.1, 1.8, 1.5, 0.9, and $0.3 \mathrm{~nm}$, respectively. The spin-cast film of polymer $\mathbf{I}$ is rougher than that of polymer II, suggesting that a less favorable interaction between chloroform and polymer I produced a more rapid film deposition, even though we can obtain a transparent $20 \mathrm{mg} / \mathrm{mL}$ homogeneous chloroform solution of this polymer. The presence of long methylene blocks in the polymer II structure accounts for the differences of the film-forming properties of the two pure polymers. During spin casting of the blend solutions, it is likely that I is precipitated ahead of II during the evaporation of the solvent causing domains to form which contribute to the roughness of the final film. When the content of the polymer II in the blend is increased, an overall smoother film is obtained. In the AFM images of the blends, uniform submicron size structures were seen, with the size of the domains decreasing as the content of polymer II increases. This indicates that phase separation of the inherently immiscible polymers occurs by a nonuniform preci pitation of the two polymers due to the difference in their $\mathrm{CHCl}_{3}$ solubility.

In Figure 3b, the PL spectrum of the 2:1 blend shows a distinct shoulder at $466 \mathrm{~nm}$, which originates from the emission of polymer I. This incomplete energy transfer is attributed to the presence of larger domains in the 2:1 blend compared to the other two blends, which is composed of relatively pure $\mathbf{I}$. Large domains in the blend inhibit energy transfer between the two polymers.

Electroluminescence. It has been shown that polymer LEDs using PEDOT/PSS coated ITO as the semitransparent anode exhibit increased stability. ${ }^{25}$ In this study, double-layer ITO/PEDOT/polymer/Ca LEDs were fabricated, whose $E L$ performance was compared with that of single-layer ITO/polymer/Ca LEDs. This also aided in understanding the efficiency improvement by adding a hole-transport layer between the emissive 


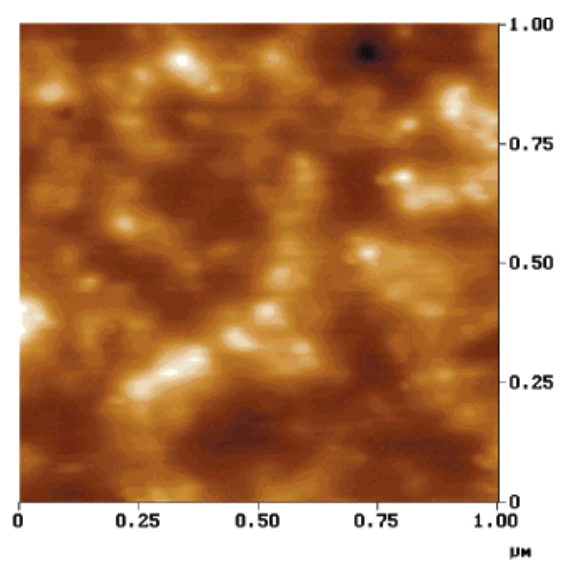

(a)

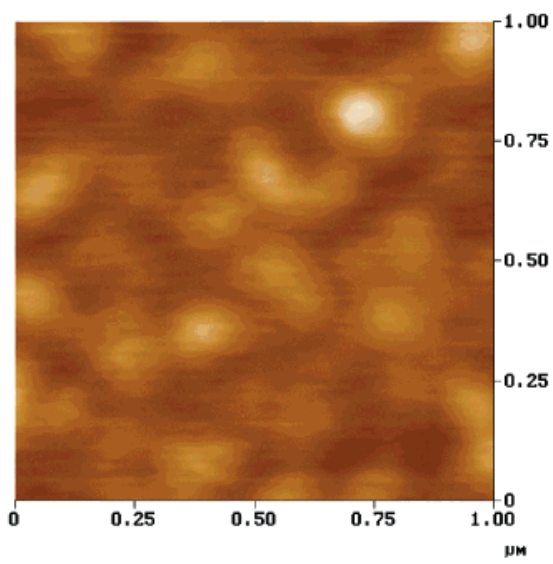

(b)

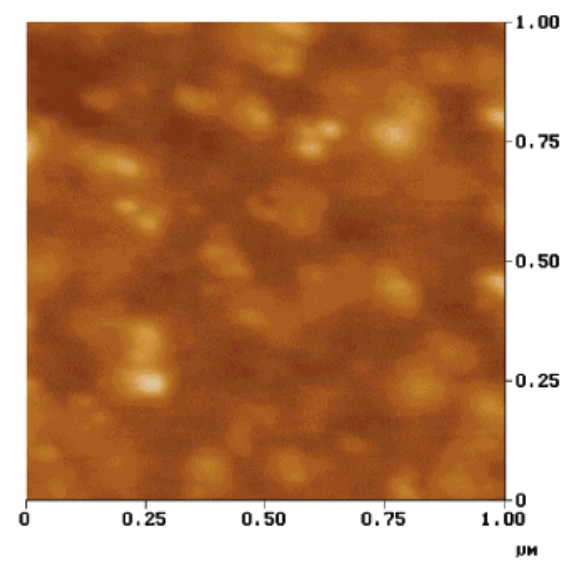

(c)

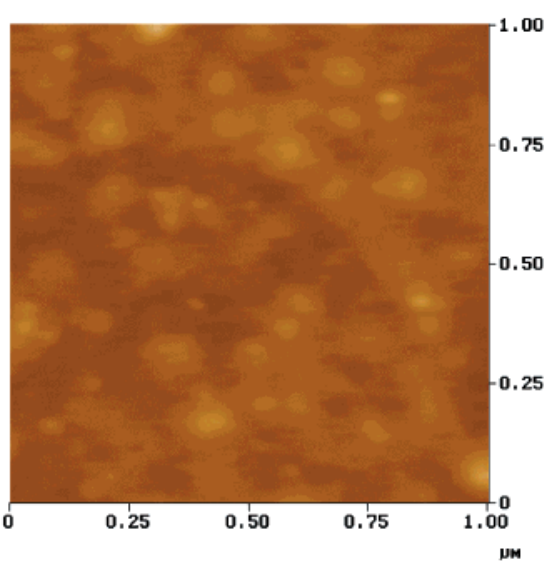

(d)

Figure 4. AFM images of polymer I (a), the $2: 1$ (b), $1: 1$ (c), and $1: 2$ (d) blends, and polymer II (e).

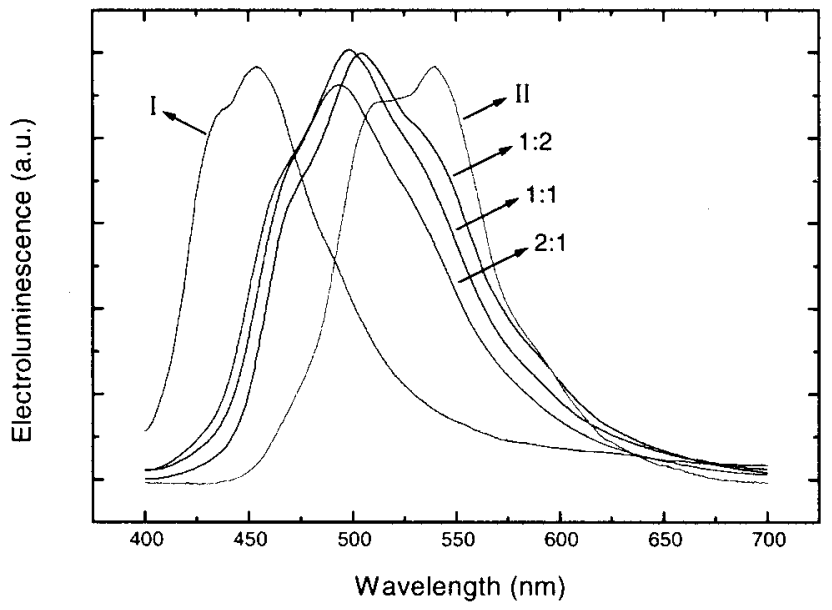

Figure 5. Electroluminescence spectra for single-layer ITO/ polymer/Ca LE Ds based on polymer I, 2:1, 1:1, and 1:2 blends, and polymer II.

polymer layer and the ITO. The EL spectra for the single-layer and double-layer LEDs are shown in Figures 5 and 6 , respectively. The peak wavelengths for EL spectra are listed in Table 1.

The EL spectra of $\mathbf{I}$ and II in Figure 5 and the corresponding solid-state PL spectra in Figure $3 \mathrm{~b}$ are similar, suggesting that both $\mathrm{PL}$ and $\mathrm{EL}$ originate from the same radiative decay process of the singlet exciton. ${ }^{26}$

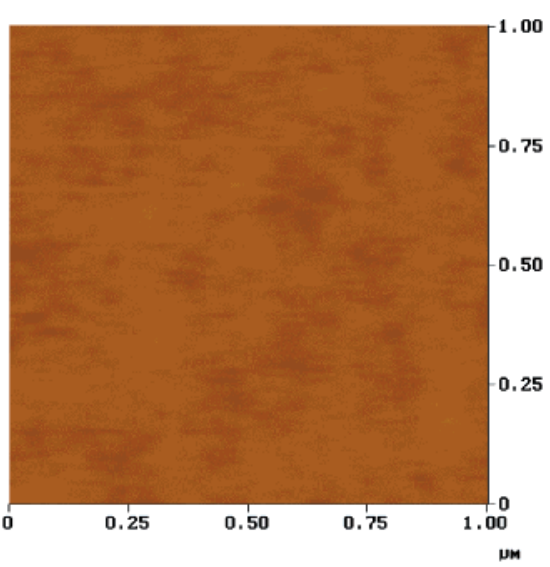

(e)
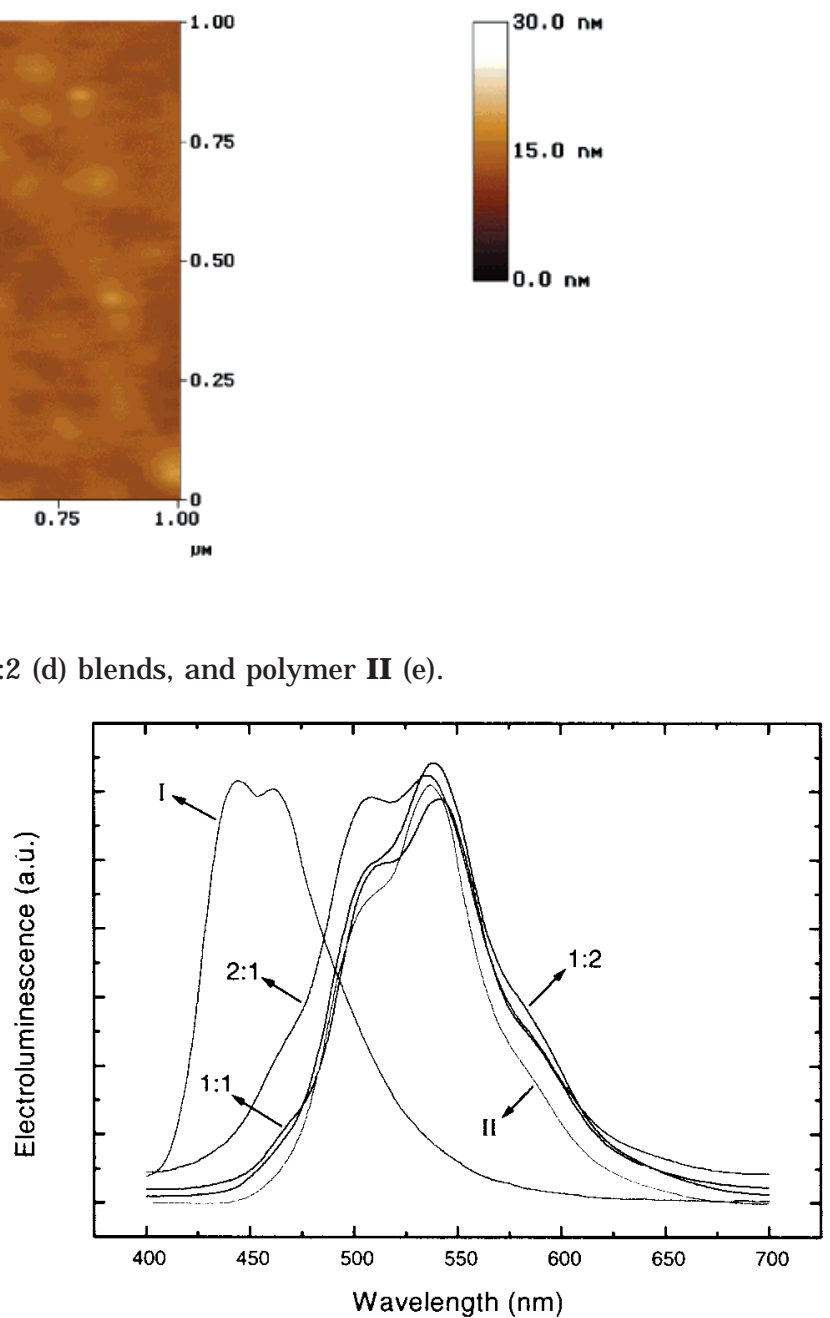

Figure 6. Electroluminescence spectra for double-layer ITO/ PEDOT/polymer/Ca LEDs based on polymer I, 2:1, 1:1, and 1:2 blends, and polymer II.

However, in the EL of single-layer LEDs based on the blends, there is a 9-15 $\mathrm{nm}$ blue shift compared with the $P L$, and also, it is noted that these EL spectra are different in shape from those of pure polymers. The absence of the characteristic emission from both I and II and the appearance of the new emissions suggest the formation of a new chromophore in the blends, which could be in the exciplex form. ${ }^{12} \mathrm{H}$ owever, the $\mathrm{E} L$ from 


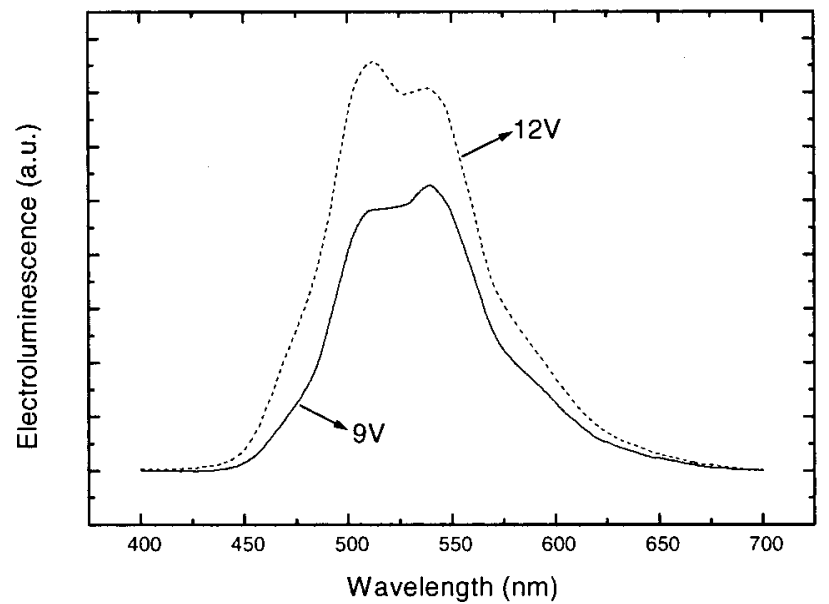

Figure 7. Voltage dependence of electrol uminescence spectra for ITO/II/Ca LED.

double-layer LEDs based on the blends shows a quite different situation (Figure 6), since one cannot observe any contribution from polymer I and there is no exciplex signature; all the EL spectra behave as that of pure II with a peak at 535-541 nm and a shoulder at 508$513 \mathrm{~nm}$ corresponding to the $0-1$ and $0-0$ transition, respectively. These phenomena suggest the existence of complete Förster energy transfer or singlet exciton transfer ${ }^{27}$ in the blends and also support the former explanation regarding the green PL from the blend films.

Singlet exciton transfer occurs on a nanosecond time scale. ${ }^{28,29}$ Because of the decrease of the hole-injection barrier by PEDOT, the singlet exciton density in the emissive polymer layer in doublelayer devices is higher than that in single-layer LEDs, and the singlet excitons born on the chain of the host polymer I might have longer lifetimes. Thus the predominant fraction of excitons can migrate to the chain of the guest polymer II before their rediative decay, as a result of which, the blend real izes almost compl ete F örster energy transfer and shows emission only from polymer II.

Voltage Dependence of EL Spectra. Figure 7 shows the voltage dependence of the EL spectra of the ITO/II/Ca device. At 9 and $12 \mathrm{~V}$, both of the spectra are composed of two peaks at 513 and $539 \mathrm{~nm}$, but the 513 $\mathrm{nm}$ peaks intensifies at higher voltage. This change in $E L$ is due to J oule heating of the sample at high current density, which results in thermochromism. ${ }^{30,31}$ We can al so attribute this phenomenon to a band gap distribution in the material. At high applied voltage, emission from the higher band gap segments dominate. ${ }^{32}$

Hole-Transport Layer Comparison. PPV and PEDOT used as hole-transport layers reduce the holeinjection barrier at the anode interface and the turn-on voltage and improve LED performance. 17,25,33 The ITO/ PPV/II/Ca device emits green light at 514 and $543 \mathrm{~nm}$, and the EL spectrum is very similar to that from the ITO/II/Ca and ITO/PEDOT/II/Ca devices, indicating that the $11 \mathrm{~nm}$ PPV layer does not function as a chromophore in this device. PPV and PEDOT reduce the turn-on vol tage from 4 to $3 \mathrm{~V}$ and to $2.5 \mathrm{~V}$, respectively. The maximum external quantum efficiencies of the ITO/ II/Ca, ITO/PPV/II/Ca and ITO/PEDOT/II/Ca devices are $5.9 \times 10^{-3} \%, 0.41 \%$, and $0.69 \%$ respectively. The PEDOT layer significantly improves the device efficiency, due to the fact that the HOMO of PEDOT (5.2/5.3 eV) lies lower than that of PPV $(5.0 \mathrm{eV}),{ }^{34,35}$ that helps to
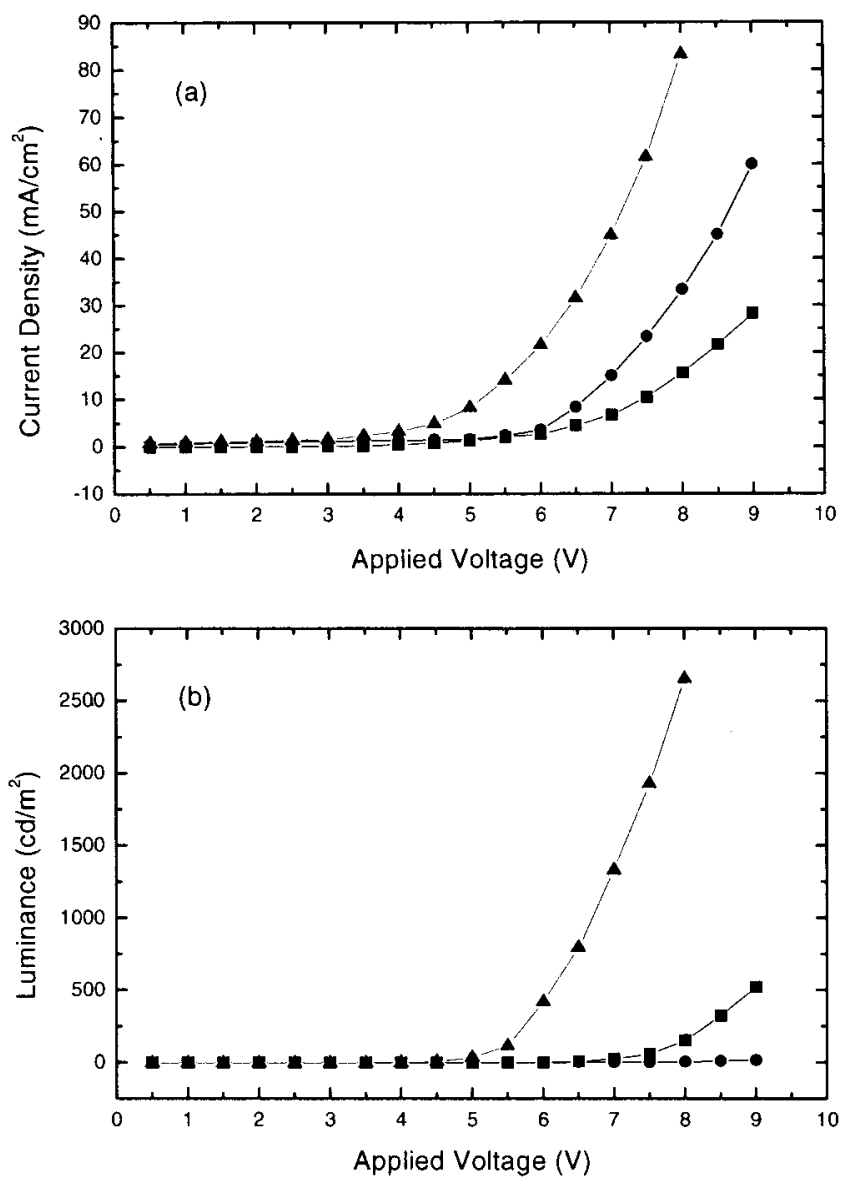

Figure 8. Current density (a) and luminance (b) vs applied voltage for ITO/II/Ca (•), ITO/PPV/II/Ca (ם), and ITO/PEDOT/ II/Ca ( $\mathbf{\Delta})$ LEDs.

provide a higher built-in field across the emitting polymer II. At $8 \mathrm{~V}$, the ITO/PEDOT/II/Ca device emits pure green light with a brightness of about $2700 \mathrm{~cd} / \mathrm{m}^{2}$ (Figure 8).

\section{Conclusions}

Two conjugated polymers, one emitting violet-blue light (I) and the other emitting green light (II), were blended with different weight ratios. Only green emission with the characteristic of polymer II was obtained in solid-state PL of the blends, suggesting a Förster energy transfer from polymer I to II, which was independent of the excitation wavelength. The large domains in the blend with higher concentration of polymer I were responsible for the incompleteness of energy transfer in such blends. In single-layer LEDs, the existence of exciplex was noted. PPV and PEDOT/ PSS used in double-layer devices improve device efficiency and reduce turn-on voltage significantly. An almost complete Förster energy transfer phenomenon was found in double-layer LEDs. This work is pertinent to future LED designs based on conjugated polymer blends aiming at tuning the emission color.

Acknowledgment. This work was supported by the Air Force Office of Scientific Research (Grant Nos. F 49620-99-1-002, F 49620-00-1-0090).

\section{References and Notes}

(1) Burroughes, J . H.; Bradley, D. D. C.; Brown, A. R.; Marks, R. N.; Mackay, K.; Friend, R. H.; Burns, P. L.; Holmes, A. B. Nature 1990, 347, 539. 
(2) Friend, R. H.; Gymer, R. W.; Holmes, A. B.; Burroughes, J . H.; Marks, R. N.; Taliani, C.; Bradley, D. D. C.; Dos Santos, D. A.; Brédas, J . L.; Lögdlund, M.; Salaneck, W. R. Nature 1999, 397, 121.

(3) Pei, Q.; Yu, G.; Zhang, C.; Yang, Y.; Heeger, A. J . Science 1995, 269, 1086.

(4) Yu, G.; Gao, J .; Hummelen, J . C.; Wudl, F.; Heeger, A. J . Science 1995, 270, 1789.

(5) Halls, J . J . M.; Walsh, C. A.; Greenham, N. C.; Marseglia, E. A.; Friend, R. H.; Moratti, S. C.; Holmes, A. B. Nature 1995, 376, 498.

(6) Yang, Y.; Heeger, A. J . Nature 1994, 372, 344.

(7) Hide, F.; Díaz-García, M. A.; Schwartz, B.J .; Andersson, M. R.; Pei, Q.; Heeger, A. J . Science 1996, 273, 1833.

(8) Tessler, N.; Denton, G. J .; Friend, R. H. Nature 1996, 382, 695.

(9) Burn, P. L.; Holmes, A. B.; Kraft, A.; Bradley, D. D. C.; Brown, A. R.; Friend, R. H.; Gymer, R. W. Nature 1992, 356, 47.

(10) Yang, Z.; Sokolik, I.; Karasz, F. E. Macromolecules 1993, 26, 1188.

(11) Andersson, M. R.; Berggren, M.; Gustafsson, G.; Hjertberg, T.; Inganäs, O.; Wennerström, O. Synth. Met. 1995, 71, 2183.

(12) Hu, B.; Yang, Z.; Karasz, F. E. J . Appl. Phys. 1994, 76, 2419.

(13) Zhang, C.; von Seggern, H.; Pakbaz, K.; Kraabel, B.; Schmidt, H.-W.; Heeger, A. J . Synth. Met. 1994, 62, 35.

(14) Hu, B.; Zhang, N.; Karasz, F. E.J . Appl. Phys. 1998, 83, 6002.

(15) McGehee, M. D.; Bergstedt, T.; Zhang, C.; Saab, A. P.; O'Regan, M. B.; Bazan, G. C.; Srdanov, V. I.; Heeger, A. J . Adv. Mater. 1999, 11, 1349.

(16) Romero, D. B.; Schaer, M.; Zuppiroli, L.; Cesar, B.; Francois, B. Appl. Phys. Lett. 1995, 67, 1659.

(17) Hu, B.; Karasz, F. E. Chem. Phys. 1998, 227, 263.

(18) Yu, G.; Nishino, H.; Heeger, A. J .; Chen, T.-A.; Rieke, R. D. Synth. Met. 1995, 72, 249.

(19) Nishino, H.; Yu, G.; Heeger, A. J .; Chen, T.-A.; Rieke, R. D. Synth. Met. 1995, 68, 243.
(20) Hu, B.; Karasz, F. E. Synth. Met. 1998, 92, 157.

(21) Förster, T. Discuss. Faraday Soc. 1959, 27, 7.

(22) Agranovich, V. M.; Galanin, M. D. Electronic Excitation Energy Transfer In Condensed Matter; North-Holland: Amsterdam, 1982.

(23) Liao, L.; Pang, Y.; Ding, L.; Karasz, F. E. Macromolecules 2001, 34, 7300 .

(24) Dogariu, A.; Gupta, R.; Heeger, A. J .; Wang, H. Synth. Met. 1999, 100, 95

(25) Cao, Y.; Yu, G.; Zhang, C.; Menon, R.; Heeger, A. J . Synth. Met. 1997, 87, 171.

(26) Baigent, D. R.; Friend, R. H.; Lee, J . K.; Schrock, R. R. Synth. Met. 1995, 71, 2171.

(27) Cleave, V.; Yahioglu, G.; Le Barny, P.; Friend, R. H.; Tessler, N. Adv. Mater. 1999, 11, 285.

(28) Sessler, J. L.; Wang, B.; Harriman, A. J . Am. Chem. Soc. 1995, 117, 704.

(29) Lemmer, U.; Ochse, A.; Deussen, M.; Mahrt, R. F.; Göbel, E. O.; Bässler, H.; Bolivar, P. H.; Wegmann, G.; Kurz, H. Synth. Met. 1996, 78, 289.

(30) Braun, D.; Heeger, A. J . Appl. Phys. Lett. 1991, 58, 1982.

(31) Braun, D.; Moses, D.; Zhang, C.; Heeger, A. J . Appl. Phys. Lett. 1992, 61, 3902.

(32) Bolognesi, A.; Bajo, G.; Paloheimo, J .; Östergård, T.; Stubb, H. Adv. Mater. 1997, 9, 121.

(33) Brown, T. M.; Friend, R. H.; Millard, I. S.; Lacey, D. J Burroughes, J. H.; Cacialli, F. Appl. Phys. Lett. 2000, 77, 3096.

(34) Brown, T. M.; Kim, J . S.; Friend, R. H.; Cacialli, F .; Daik, R.; Feast, W. J . Appl. Phys. Lett. 1999, 75, 1679.

(35) Colvin, V. L.; Schlamp, M. C.; Alivisatos, A. P. Nature 1994, $370,354$.

MA011112T 